\title{
Rapidly expanding exophthalmos: an unusual presentation of small cell lung cancer
}

\author{
RICHARD F SPAIDE,' ELDER GRANGER, ' BRADLEY D HAMMER,' \\ FREDDIE J NEGRON, ${ }^{3}$ AND PATRICK G PAGLEN ${ }^{4}$ \\ From the ${ }^{1}$ Ophthalmology Service, the ${ }^{2}$ Oncology Service, and the ${ }^{3}$ Pulmonary Service of Landstuhl Army \\ Regional Medical Center, and the ${ }^{4}$ Ophthalmology Service of the Wiesbaden Air Force Regional Medical \\ Center, Federal Republic of Germany
}

SUMMARY A 61-year-old male presented with a rapidly progressive exophthalmos from small cell lung cancer metastatic to the right orbit. His vision in that eye was 20/200, and his intraocular pressure was $36 \mathrm{mmHg}$. The orbital metastasis responded dramatically to chemotherapy. One week after starting the chemotherapy the patient did not have exophthalmos, his vision was 20/20, and three weeks later the intraocular pressure was $12 \mathrm{mmHg}$.

Small cell lung cancer (SCLC) is one of the most aggressively metastatic tumours. ${ }^{1}$ It is the fifth leading cause of cancer death in the US, and only 1 to $2 \%$ of patients with disseminated disease at diagnosis achieve lasting remissions. ${ }^{2}$ This report describes a patient who presented with a rapidly progressing exophthalmos from an SCLC and his good response to chemotherapy.

\section{Case report}

A 61-year-old white male developed acute swelling of his right eyelids, and a diagnosis of preseptal cellulitis was made. The patient did not respond to antibiotics, so he was referred for further examination and treatment. On presentation he had a fullness of the right eyelids and temporal fossa. The globe was proptosed by about $10 \mathrm{~mm}$ and embedded in an indurated tumour mass that raised the conjunctiva. The preauricular node was enlarged on the right. The visual acuity was 20/200 in the right eye, 20/30 in the left eye, and there was a $2+$ afferent pupillary defect in the right. The intraocular pressure was $36 \mathrm{mmHg}$ in the right eye and 12 in the left.

Computed tomography of the orbit (Fig. 1) revealed a large homogeneous tumour in the right temporal fossa that continued round the edge of the right orbital margin into the orbit to the superior orbital fissure. The tumour extended round the medial part of the eye and encompassed the lacrimal

Correspondence to Richard F Spaide, MD, Box 27, Landstuhl Army Regional Medical Center, APO NY 09180, USA. sac. The posterior part of the globe was distorted, apparently because it was tethered by the stretched optic nerve. Chest roentgenography (Fig. 2) showed a widened mediastinum with asymmetrical bilateral hilar adenopathy.

A biopsy of the right lateral edge of the orbit revealed metastatic SCLC. We had planned to administer radiation therapy to the orbit for palliation, but our hospital does not have radiotherapy

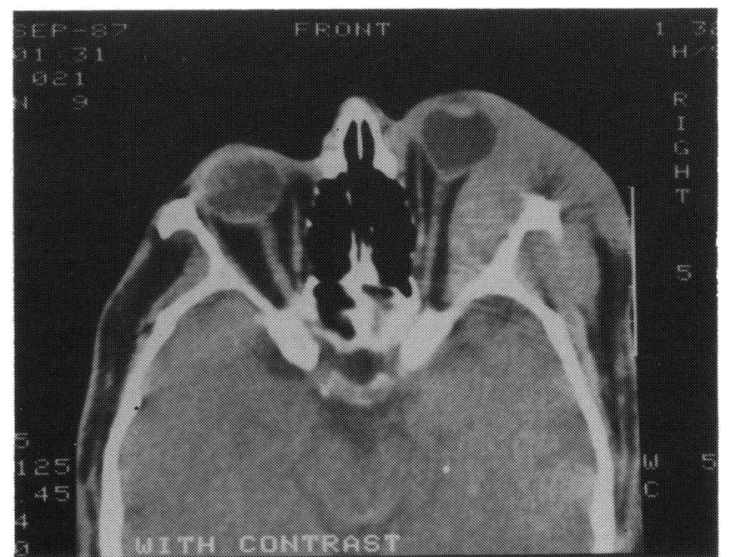

Fig. 1 Pretreatment axial computed tomograph $(C T)$ with contrast of the orbits. The eye, embedded in tumour, is deformed by compressive effects and by tethering of the optic nerve. The optic nerve has some redundancy in the orbit, and so it usually does not lie in one plane (left eye). The right optic nerve is stretched taught. 


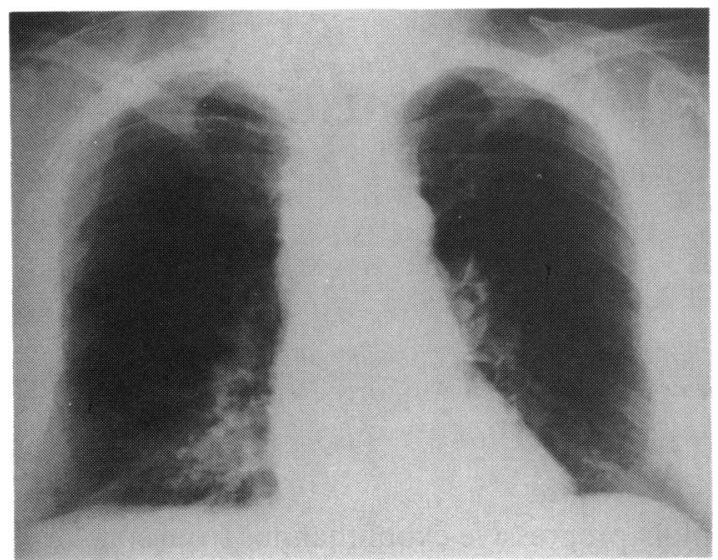

Fig. 2 Pretreatment chest $\mathrm{x}$-ray showing widening of the mediastinum, right paratracheal and aortopulmonic window abnormalities, minimal air bronchograms, and bilateral plural effusions.

capabilities, and scheduling problems would have delayed treatment for one week. In the interim we administered induction chemotherapy directed against small cell lung cancer: Cytoxan (cyclophosphamide) $1000 \mathrm{mg} / \mathrm{m}^{2}$ on day 1 , Adriamycin (doxorubicin) $45 \mathrm{mg} / \mathrm{m}^{2}$ intravenously on day 1 , VP 16 (etopside) $80 \mathrm{mg} / \mathrm{m}^{2}$ intravenously on days 1,2 , and 3. The orbital tumour had a good response to the chemotherapy. At one week after starting therapy he had minimal thickening of the lateral orbital rim and a faint subconjunctival infiltration. He had no proptosis; he was orthophoric in all fields of gaze, and his visual acuity was $20 / 20$. The primary tumour in the lung completely resolved after three cycles of chemotherapy. The computed tomograph of his orbit showed a resolution of the tumour mass (Fig. 3). The intraocular pressure was $12 \mathrm{mmHg}$ three weeks after treatment started.

\section{Discussion}

We wanted to treat this patient with radiation, but this proved unnecessary. Since patients with SCLC have to be treated with chemotherapy anyway, it

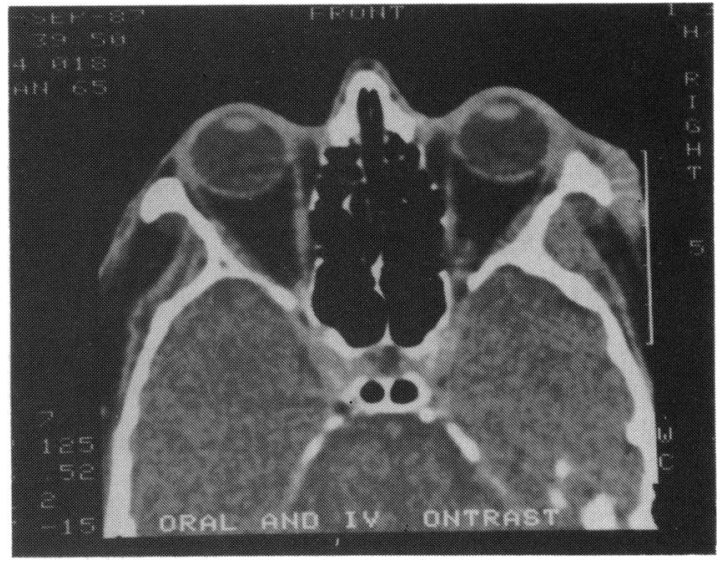

Fig. 3 Axial CT of the orbits with contrast three weeks after the initiation of treatment showing the resolution of the exophthalmos, with a normal ocular morphology.

Thickening remains in the temporal fossa and adjacent to the lateral orbital tubercle.

might be better to start the chemotherapy immediately and use radiation therapy only if chemotherapy proves unsuccessful. Indeed, at one time superior vena caval obstruction in small cell lung cancer was considered a medical emergency requiring immediate radiotherapy, but now induction chemotherapy is the treatment of choice. ${ }^{3}$ We know of no other case of an orbital metastasis from SCLC treated with chemotherapy, but a previous report described a patient with SCLC metastatic to the iris who also had a striking response to chemotherapy. ${ }^{4}$

\section{References}

1 Iannuzzi MC, Scoggin CH. Small cell lung cancer. Am Rev Respir Dis 1986; 134: 593-604.

2 Bunn PA. Recent advances in the biology and treatment of smallcell lung cancer. Adv Oncol 1986; 4: 9-15.

3 Sculier JP, Evans WK, Feld R, et al. Superior vena caval obstruction syndrome in small cell lung cancer. Cancer 1986; 57: $847-51$.

4 Sierocki JS, Charles NC, Schafrank M, Wittes RE. Carcinoma metastatic to the anterior ocular segment: response to chemotherapy. Cancer 1980; 45: 2521-3.

Accepted for publication 3 October 1988. 